\title{
Sociodemographic and substance use correlates of repeated relapse among patients presenting for relapse treatment at an addiction treatment center in Kolkata, India
}

\author{
*Sau M, Mukherjee A, Manna N, Sanyal S \\ Department of Community Medicine, Medical College Kolkata, India
}

\begin{abstract}
Background: In India, substance abuse has infiltrated all socio-cultural and economic strata causing loss of productivity. Prevention of relapse is crucial for its control.

Objectives: To find out the pattern of substance use, relapse rate, its association with various socio-demographic factors and treatment related issues.

Methods: An observational study with cross-sectional design during April 2009-March 2010 at a de addiction centre was conducted among consecutive 284 clients admitted with relapse. They were detoxified earlier in the same centre. Data were collected by interviewing clients with schedule and clinical examination.

Results: Brown sugar (an adulterated form of Heroin) was primary drug of abuse in urban area contrary to alcohol in rural area. Commonest age of initiation was between $15-20$ years. Polydrug abusers $(59.1 \%)$ were common. Only $31.3 \%$ of the relapse cases took regular follow up. Common psychiatric illnesses were anxiety $(44.7 \%)$ and depression (30.6\%). Peer pressure $(77.8 \%)$ was commonest cause of relapse. Significantly higher relapse episodes were present with increasing age, Muslim religion, ever marriage, poor literacy, current unemployment, living in nuclear rather than joint family, early age of initiation, longer duration of abuse and no follow up.

Conclusion: Regular follow up with family, peer and social support are essential along with vocational rehabilitation to prevent relapse.
\end{abstract}

Key words: drug abuse, relapse, addiction severity index, withdrawal, alcohol, brown sugar.

African Health Sciences 2013; 13(3): 791 - 799 http://dx.doi.org/10.4314/ahs.v13i3.39

\section{Introduction}

Substance abuse causes acute and chronic physical, psychological and social effects in varying amounts along with serious social problems in the form of crime, unemployment, family dysfunction and disproportionate use of medical care. Science has not yet explained fully the physiological and psychological processes leading to drug abuse. Substance abuse affects above 50 million people worldwide. Abuse of legally prescribed drugs is also increasing alarmingly. The annual worldwide drug revenues are now next only to arms trade. ${ }^{1}$

In India, the abuse of alcohol, cannabis and raw opium has been traditionally known. The abuse of synthetic narcotic drugs and psychotropic substances is comparatively new. Substance abuse has

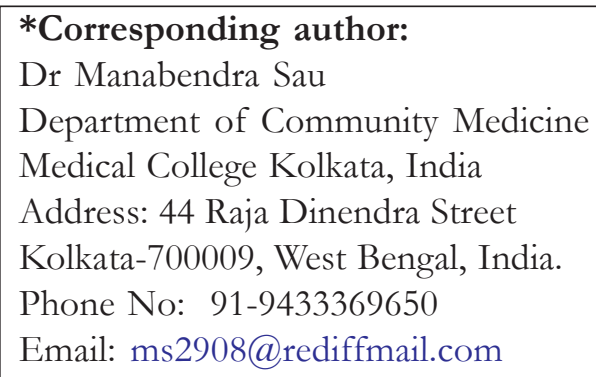

infiltrated all socio-cultural and economic strata causing loss of productivity. ${ }^{2}$ Family stress, lack of coping skills, peer pressure, personality disorder, co morbid psychiatric illnesses, social stress and market forces act as risk factors. ${ }^{3}$ Survey shows that around $20-30 \%$ of adult males and $5 \%$ of adult females use alcohol while $57 \%$ of the male and $10.8 \%$ of the female drug users consume opiates in some form or other. ${ }^{4}$ Rapid assessment survey on substance abuse shows that the primary abused drugs are heroin $(36 \%)$, other opiates $(29 \%)$ and cannabis $(22 \%) ; 75 \%$ of addicts start drug abuse before 20 years of age; in urban areas heroin abuse is more while in other sites cannabis abuse is more. ${ }^{5}$

Addiction is to be viewed as a chronic disorder in which relapse is the natural part of recovery process. ${ }^{6}$ Relapse is considered when a person returns to even a single usage of a substance or process of which they had previously established abstinence. Prevention of relapse is crucial for control of substance abuse disorder. The goals of treatment are abstinence from/ reduction of use of substance, reduction of frequency and severity of relapses and 
improvement of psychological and social adaptive functioning. ${ }^{7}$

Information on substance abuse in India is mostly anecdotal with scarcity of data and reports available only from small-scale surveys. It is important in Indian scenario to explore the different factors related with drug abuse. Drug abuse is a chronic illness. Aim of holistic management of drug abuse is to make the clients in sustainable period of drug free state. It has been observed that repeated relapse is common among drug abusers. The present study is therefore an effort to find out the pattern of substance use, morbidity pattern, relapse rate with its association with various socio-demographic factors and treatment related issues.

\section{Methods}

We conducted an observational study with crosssectional design during April 2009-March 2010 at a de addiction centre run by a non Government organization, pioneer in the field of treatment and rehabilitation of drug abusers funded by Ministry of Social Justice and Empowerment, Government of India. Out of the 4 Government sponsored deaddiction centers situated in Kolkata, one was selected by simple random sampling method. The selected centre is situated in Sonarpur of District South 24 Parganas, West Bengal. The centre had 30 inpatient beds and 24 hour helpline for abusers and follow up facilities. The clients come either directly or via referral from the districts of West Bengal and other states. Average admission rate was 450 per year. $60 \%$ of the total admissions were relapses. A total of consecutive 284 clients admitted with relapse were taken as sample population. Patients who had been detoxified previously at that center were taken as "relapsers" in the study. Patients stay on an average for 1 month for completion of detoxification course that includes withdrawal and co-morbidity management.

Necessary ethical clearance along with permission from the Director of the Institute was taken and data collected by interviewing clients with predesigned and pretested schedule containing questions to explore information regarding sociodemographic and addiction related variables. Clinical examination (physical and psychiatric) was done by one researcher with desired training in this field. History sheets filled up during admission and previous health records were taken as secondary data. The completeness of the proforma was ensured by cross checking. The patients attending with minimum one relapse with stable general conditions without signs and symptoms of withdrawals were included in the study. Some clients needed more than one sitting after giving informed consent. The patients were interviewed at the earliest possible time of their attending stable general condition (mean 13.4 days with SD 1.9 days from date of admission to time of interview).

The addiction severity ratings were done according to addiction severity index (ASI) scale $3^{\text {rd }}$ edition validated and used by UNODC (United Nations Office of Drugs and Crime). ${ }^{8}$ The scales range from $0-9$. Each rating was based upon the patient's history of problem symptoms, present condition and subjective assessment of their treatment needs in a given area. The scoring was given in the areas of medical status, employment/support status, drug use, alcohol use, legal status, family relationship and psychiatric status. Total score was calculated and severity measured as per Likert's scale. The scale was translated into local vernacular comprehensible to the patient with content validation by 5 subject experts.

Drug is defined as any substance that when taken into the living organism may modify one or more of its functions and abuse is a nonmedical, unsanctioned and maladaptive pattern of use of substances irrespective of its adverse physical psychological and social consequences. Withdrawal is a short lasting syndrome characterized by cluster of symptoms, often specific to the drug use, which develops from total or partial withdrawal of a drug usually after repeated and / or high dose. Detoxification is a process by which an individual is cleansed of the toxic effects of substances he/she was addicted to. After Care is the provision of services for a recovering addict after detoxification to ensure readjustment and normal functioning within the community. ${ }^{9}$

The data were tabulated in Microsoft Excel 2007 and analyzed by Epi info 3.5.1 and SPSS 16.0 software for proportions and chi-square tests as test of significance and binomial logistic regression analysis.

\section{Results}

A total of 284 persons were interviewed and examined during the study period which revealed that majority ( $88 \%$ ) belonged to $20-49$ year age group with mean age 31.2 years and Standard deviation 7.1 years. Majority were Hindus (64.8\%) and males $(96.8 \%)$. Most of the relapse cases were 
employed (61.3\%), currently married $(45.8 \%)$ and illiterates $(10.2 \%) .34 .2 \%$ were below poverty line according to Modified Prasad socio-economic scale ${ }^{10}$ (based upon per capita monthly family income in Indian currency regularly updated as per consumer price index of India); $57.7 \%$ belonged to nuclear families and maximum proportion were urban residents $(60.5 \%)$. (table 1$)$

Proportion of alcohol as primary drug abuse in urban and rural area were $73.4 \%$ and 26.6 $\%$ respectively where as brown sugar (an adulterated form of Heroin) abuse in urban area was $78.1 \%$. In
$80 \%$ of cases age of initiation of drug abuse was between 18-25 years. Most common drug on initiation was cannabis. It was observed that shifting of drug from initial to last detoxification was $42.9 \%$ to $1.4 \%$ for cannabis, $92 \%$ to $38 \%$ for alcohol and $6.3 \%$ to $51.4 \%$ for brown sugar. Injecting drug users were $7.8 \%$. Forty nine percent clients had been taking drugs for 10-20 years. All of them used tobacco. Poly drug abusers were more common. Commonest route was inhalation followed by oral. (table 2)

Table 1 : distribution of study sample according to socio-demographic factors

\begin{tabular}{|c|c|c|c|}
\hline Attributes & & $\begin{array}{l}\text { Frequency } \\
(\mathrm{n}=284)\end{array}$ & Percentage \\
\hline \multirow[t]{3}{*}{ Age (in completed years) } & $10-19$ & 26 & 9.2 \\
\hline & $20-49$ & 251 & 88.4 \\
\hline & $50 \&$ above & 7 & 2.4 \\
\hline \multirow[t]{2}{*}{ Sex } & Male & 275 & 96.8 \\
\hline & Female & 9 & 3.2 \\
\hline \multirow[t]{3}{*}{ Religion } & Hindu & 184 & 64.8 \\
\hline & Muslim & 48 & 16.9 \\
\hline & Others & 52 & 18.3 \\
\hline \multirow[t]{3}{*}{ Marital status } & Currently married & 130 & 45.8 \\
\hline & Unmarried & 116 & 40.8 \\
\hline & Ever married & 38 & 13.4 \\
\hline \multirow[t]{4}{*}{ Literacy status } & Illiterate & 29 & 10.2 \\
\hline & Up to primary & 74 & 26.0 \\
\hline & Secondary & 130 & 45.8 \\
\hline & Higher secondary and above & 51 & 18.0 \\
\hline \multirow[t]{3}{*}{ Present occupation } & Employed & 174 & 61.3 \\
\hline & Never employed & 79 & 27.8 \\
\hline & Currently unemployed & 31 & 10.9 \\
\hline \multirow[t]{6}{*}{ Social class (modified Prasad scale) } & VI (Below poverty line) & 97 & 34.2 \\
\hline & $\mathrm{V}$ (poor) & 109 & 38.4 \\
\hline & IV(lower middle) & 27 & 9.5 \\
\hline & III (upper middle) & 21 & 7.4 \\
\hline & II(upper) & 12 & 4.2 \\
\hline & I(upper high) & 18 & 6.3 \\
\hline \multirow[t]{2}{*}{ Type of family } & Nuclear & 164 & 57.7 \\
\hline & Joint & 120 & 42.3 \\
\hline \multirow[t]{2}{*}{ Place of residence } & Urban & 172 & 60.5 \\
\hline & Rural & 112 & 39.5 \\
\hline
\end{tabular}


Table 2: distribution of study sample according to pattern of drug abuse $(n=284)$

\begin{tabular}{llll}
\hline Pattern of drug abuse & & Frequency & Percentage \\
\hline Type of currentdrug abused & Brown sugar & 146 & 51.4 \\
& Alcohol & 109 & 38.3 \\
& Morphine & 22 & 7.8 \\
& Cannabis & 4 & 1.4 \\
Age of initiation (in yrs) & Sedative & 3 & 1.1 \\
& $<18$ & 17 & 6 \\
Duration of drug abuse (in yrs) & $18-25$ & 227 & 80 \\
& $>25$ & 40 & 14 \\
Pattern of initial drug abused & $<10$ & 110 & 38.7 \\
& $10-20$ & 139 & 49.0 \\
& $>20$ & 35 & 12.3 \\
& Cannabis & 122 & 43.0 \\
Nobacco use pattern & Alcohol & 102 & 35.9 \\
& Sedatives & 32 & 11.3 \\
& Brown Sugar & 18 & 6.3 \\
& Morphine & 10 & 3.5 \\
Number of drug abused & Multiple & 168 & 59.1 \\
& Single & 116 & 40.9 \\
Route of drug abuse*(multiple choice) & Combination & 157 & 55.3 \\
Drug abuse in social situation & Smokeless & 65 & 22.9 \\
& tobacco & & \\
& Smoking & 62 & 21.8 \\
& Inhalation & 152 & 53.5 \\
& Oral & 150 & 52.8 \\
& IV/IM & 22 & 7.8 \\
& In groups & 188 & 66.2 \\
& Alone & 96 & 33.8 \\
\hline
\end{tabular}

Commonest combination with relapses was alcohol with cannabis $(20.1 \%)$. Most of the relapse cases were put on conventional treatment that included withdrawal of relapsed drug, management of withdrawal symptoms and co-morbidities with rehabilitation. Substitution therapy is a form of nonconventional treatment. Only $31.3 \%$ of the clients with relapse were on regular follow up. Relapses within first year of follow up were more common. $75.4 \%$ had a single episode of relapse last year. Mean number of relapse episodes were 1.4 (SD 0.8) for the patients. Moderately severe addiction calculated by ASI scoring was more common among alcohol addicts (table 3 ).

Co morbid psychiatric illness was present in 260 clients. The common illnesses were anxiety (44.7\%), depression (30.6\%) and paranoid delusion $(9.8 \%)$. Suicidal ideas were present among $1.4 \%$ of the clients with $0.7 \%$ cases reporting attempted suicide. $23.9 \%$ of the relapse cases reported some stressful events before current episode of relapse.
Common physical illnesses were anemia (64.1\%), respiratory illness $(42.6 \%)$, glossitis $(27.8 \%)$, hypertension $(5.6 \%)$, diabetes $(2.1 \%)$, tuberculosis $(1.4 \%)$ and sexually transmitted diseases $(1.4 \%)$.

Most of the relapse cases $(71.1 \%)$ knew that addiction is not curable, drug abuse is injurious to health $(96.8 \%)$ and all of them knew that treatment is given by NGO run hospital while $7.8 \%$ opined that government hospitals also provide detoxification treatment. Peer pressure $(77.8 \%)$ was the commonest cause of relapse cited followed by acting out $(62.7 \%)$, family pressure $(20.1 \%)$ and unemployment $(27.5 \%)$. The clients wanted to quit $\operatorname{drug}(\mathrm{s})$ to come to the mainstream of life $(58.1 \%)$, to support family $(53.2 \%)$ and to get relief from pain $(48 \%)$. Irregular work-attendance $(47.6 \%)$ was less common among service holders (salaried employee in government or private sector) compared to self employed abusers (53.8\%). 
Table 3: distribution of study sample according to relapse and its management $(n=284)$

\begin{tabular}{llll}
\hline Relapse and its management & Frequency $(\mathbf{n}=284)$ & Percentage \\
\hline Severity of addiction & Not severe & 2 & 0.7 \\
& Slightly severe & 88 & 31.0 \\
& Moderately severe & 105 & 37.0 \\
& Considerably severe & 73 & 25.7 \\
& Extremely severe & 16 & 5.6 \\
Severity of withdrawal & Mild & 72 & 25.4 \\
& Moderate & 177 & 62.3 \\
Stressful event before & Severe & 35 & 12.3 \\
last relapse & Present & 68 & 23.9 \\
Relapse episodes & Obsent & 216 & 76.1 \\
& Once in last year & 214 & 75.4 \\
Type of treatment & Conventional & 70 & 24.6 \\
Pattern of follow up & Non conventional & 12 & 95.7 \\
& Irregular & 107 & 4.3 \\
& Regular & 89 & 37.7 \\
& No follow up & 88 & 31.3 \\
\hline
\end{tabular}

Table 4: association of relapse rate with socio-demography, abuse and follow up pattern $(n=284)$

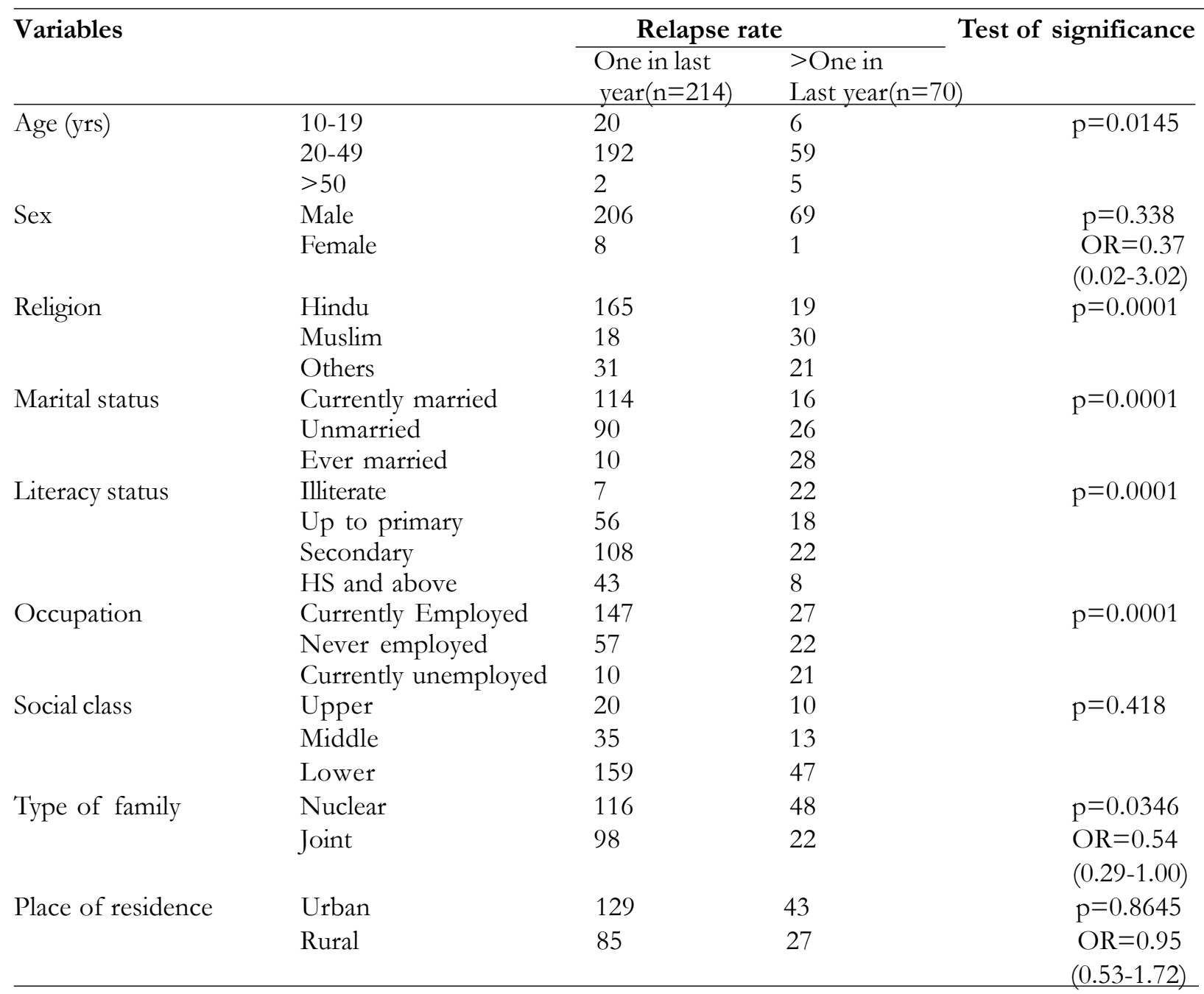




\section{Continuation of table 4}

\begin{tabular}{llccc}
\hline Variables & & Relapse rate & Test of significance \\
\cline { 2 - 4 } & & $\begin{array}{c}\text { One in last } \\
\text { year(n=214) }\end{array}$ & $\begin{array}{c}\text { > One in } \\
\text { Last year(n=70) }\end{array}$ & \\
\hline Age of initiation (Years) & $<18$ & 5 & 12 & $\mathrm{p}=0.0001$ \\
& $18-25$ & 177 & 50 & \\
Duration of use (Years) & $>25$ & 32 & 8 & $\mathrm{p}=0.0001$ \\
& $<10$ & 99 & 11 & \\
Pattern of follow up & $10-20$ & 107 & 32 & $\mathrm{p}=0.0001$ \\
& $>20$ & 8 & 27 & \\
& Regular & 87 & 2 & \\
& Irregular & 85 & 22 & \\
& Nil & 42 & 46 & \\
\hline
\end{tabular}

Table 4 depicts association of relapse episodes with socio-demographic factors, abuse pattern and follow up to treatment pattern. Statistically significantly higher relapse rate was present with increasing age, Muslim religion, ever married population, poor literacy level, current unemployment, living in nuclear family rather than joint family, early age of initiation, longer duration of abuse and no follow up $(p<0.05)$.

Significantly related attributes were tested in table 5 by binomial logistic regression analysis to determine main confounding effects and share of factors in table 4 by estimation of Cox and Snell pseudo R square and regression equation. Age (1019 years), Hindu religion, currently married status, being employed at present and being on follow up treatment were significant protective factors from increased rate of relapse $(\mathrm{p}<0.05)$.

The reference categories were: age 20 years or more, religion Muslims and others, unmarried or ever married, literacy (literate up to any standard combined), currently unemployed or never employed, joint family, age of initiation 18 years and above, duration of drug use 10 years and above and no follow up at all. Cox and Snell pseudo R square 0.47. -2 log likelihood ratio 138.58.

\section{Discussion}

A descriptive cross-sectional study was conducted among the relapse cases admitted in a de-addiction centre in Kolkata. The study population were mostly males and between $20-29$ years of age (37\%). In a study $^{5}$ by Ministry of Social Justice and Empowerment in 33 cities in India revealed that commonly affected age group was 16-35 years whereas studies conducted in Bangladesh ${ }^{11,12}$, USA 13. Vietnam ${ }^{14}$ found that mean ages of drug abusers were 25-35, 20-25, 25-35 and 27 years respectively. Nessa et al reported that $91 \%$ of drug addicts were young and adolescents ${ }^{15}$. Present study revealed that majority were Hindus (64.8\%) whereas national survey found no significant difference in religion ${ }^{5}$.

National survey found that $29 \%$ of the drug abusers were illiterates and significant number of them came from lower strata. Marital Status did not contribute to drug abuse. ${ }^{5}$ We found that $10.2 \%$ were

Table 5: Parameter Estimates in binomial logistic regression analysis for predicting relapse (more than once/year)

\begin{tabular}{lllllll}
\hline Predictors & B & S.E. & Wald & df & Sig. & Exp(B) \\
\hline Age (10-19 years) & -3.245 & 1.473 & 4.851 & 1 & $\mathbf{. 0 2 8}$ & .039 \\
Religion (Hindu) & -5.147 & 1.039 & 24.545 & 1 & $\mathbf{. 0 0 0}$ & .006 \\
Marital status (currently married) & -2.517 & .681 & 13.659 & 1 & $\mathbf{. 0 0 0}$ & .081 \\
Literacy status (Illiterate) & 1.270 & 1.426 & .793 & 1 & .373 & 3.561 \\
Occupation (Currently employed) & -1.518 & .588 & 6.672 & 1 & $\mathbf{. 0 1 0}$ & .219 \\
Family type ( Nuclear) & 2.943 & .977 & 9.069 & 1 & $\mathbf{. 0 0 3}$ & 18.973 \\
Age of initiation (<18 years) & .451 & 1.511 & .089 & 1 & .765 & 1.570 \\
Duration of use (<10 years) & -.116 & .954 & .015 & 1 & .903 & .891 \\
Pattern of follow up (Yes) & -2.403 & .549 & 19.184 & 1 & $\mathbf{. 0 0 0}$ & .090 \\
Constant & 2.941 & .770 & 14.589 & 1 & $\mathbf{. 0 0 0}$ & 18.926 \\
\hline
\end{tabular}


illiterates; $40.8 \%$ were unmarried; $10.9 \%$ were unemployed; $34.15 \%$ cases had per capita income (PCI) of family per month < Rs 1000 . Study at Tihar jail in India (2001) $)^{16}$ among 6800 male drug abusers found that commonest age group was 21-25 years; $50 \%$ were illiterates; $44 \%$ were unmarried; $8 \%$ were unemployed.

Present study revealed that brown sugar (adulterated form of Heroin) and alcohol were the most commonly abused drugs in urban and rural areas respectively. Heroin was the most common abused drug in studies conducted in Bangladesh ${ }^{15}$, Tihar jail ${ }^{16}$ $(82 \%)$, in Delhi by Raj et al ${ }^{17}(58 \%)$, Vietnam ${ }^{14}$, Pakistan national survey (2000) (46\%) ${ }^{18}$ and Arunachal Pradesh ${ }^{19}$.

In present study, most of the abusers initiated drug use between 18-25 years of age and most common initial drug of abuse was cannabis similar to the findings of Household Survey $(1996)^{20}$ in USA. Mean age of initiation of tobacco and alcohol intake were 20.1 and 21.6 years respectively in a study conducted by Hazarika et al in border area of Assam and Arunachal Pradesh (2000) ${ }^{21}$.

It was also observed that shifting of choice of chemicals were more in cannabis than to brown sugar and less with alcohol. Commonest route of addiction was inhalation followed closely by oral. Similar findings were noted in the study conducted in Pakistan ${ }^{18}$.

We found that anemia, respiratory illness and glossitis were most common physical illnesses while anxiety was most common psychiatric illness followed by depression. Similar physical and mental dysfunctions were reported in Tihar jail study ${ }^{16}$ among $65 \%$ of the drug abusers while Regier et al $(1990)^{22}$ found anxiety, mood and personality disorder the most common. The abusers mostly used polysubstances and usage began at early age ${ }^{22}$. Present study found that maximum persons were taking poly drugs also similar to the findings of Chaturvedi et $\mathrm{al}^{23}$. Insomnia, irritability and body ache were common morbidities as reported by Divya Agarwal et $\mathrm{al}^{24}$ while Montoya et al (1995) ${ }^{25}$ reported that among treatment seekers for drug abuse 64\% had psychiatric illnesses on presentation.

Maximum proportion (49\%) of clients with relapse were taking drugs for 10-20 yrs. Anthony and Helzer reported average duration of addiction to be 6.1 years $^{26}$.

In the present study $71.1 \%$ of the clients told that drug abuse was not curable. Most common cause of relapse was peer pressure $(77.8 \%)$ followed by curiosity. Several other studies identified risk factors for substance abuse and relapse like mental illness, lack of protective housing, social and neighborhoods problems, inter personal pressure, isolation, no recreation, lack of trust and social security ${ }^{27-30}$. We found that $58.1 \%$ relapse cases wanted to quit drugs to return to normal life while $53.2 \%$ said that they wanted to support their family. Heymen et $\mathrm{al}^{31}$ (1996) discussed problems regarding quitting drug abuse. $79.9 \%$ blamed peers for their relapse while $24.7 \%$ blamed friends and $9.9 \%$ put the onus on neighbors and relatives.

As the present study is an institution based descriptive study, there may be recall bias, misclassification bias and conscious falsification which could not be totally excluded. We have only included patients with relapse. Estimation of relative risk was not done. Long duration of abuse pattern in addicts with non adherence to treatment regime leads to different physical and psychological morbidities along with moderately severe withdrawal symptoms. Peer pressure was commonest cause of relapse cited and opting for mainstream of life was the major stimulant to quit.

\section{Conclusion}

Psychiatric illnesses are frequent among relapse cases, so family members have got a definite role in providing support and care to the relapse cases. In our study the findings of lower relapse cases among members of joint families and married persons rather than nuclear families and divorced or separated persons give support to this view. Financial security in the form of employment is critical for recovery and social rehabilitation of relapse cases. It is observed that regular follow up care of patients is needed, as with regular follow up patients with lesser relapse find confidence and allows better commitment to therapy. Larger cohort studies with standard psychiatric assessment tools could enrich our knowledge.

\section{References}

1. United Nations office on drugs and crime. Investing in drug abused treatment, a discussion paper for policy makers; Vienna Austria. United Nations International Drug Control Programme. New York, 2003.

2. National Institute of Social Defense (NISD) Govt of India (2005). Manual on prevention of substance abuse in small enterprises. NISD Govt. of India, New Delhi. 
3. Sadock B.J. and Sadock V.A. Caplan and Sadock's Comprehensive text book of psychiatry. $7^{\text {th }}$ edition. Lippincott Williams and Wilkins publishers; 2000: 942-49.

4. Govt of India (2010), Annual report 2009-10, Ministry of health and family welfare, New Delhi.

5. Kumar S. M. (2002). Rapid assessment survey of drug abuse in India. Ministry of social justice and empowerment, Government of India and United Nations office on drugs and crime (UNODC), Regional office for South Asia. [internet] (cited on 25.10.2011). Available from http://www.unodc.org /pdf/india/ publication /ras/06_executive summary.pdf

6. Ministry of Social Justice and Empowerment, Government of India. "Annual reports, 199798, 1998-99, 1999-2000 and 2000-2001." Ministry of Social Justice and Empowerment, Government of India, New Delhi.

7. Murthy P. Introduction. In: Murthy P, Nikketha SBS editors. Psychosocial interventions for persons with substance abuse theory and practice. Bangalore: National Institute of Mental Health and Neuro Sciences De-Addiction Centre; 2008: 64.

8. Addiction severity index treatment planning manual. [internet] (cited on 1.1.2010) Available from http:// www.unodc.org / docs / treatment /1.ASI_Manual.pdf

9. Ahuja N. Short text book of psychiatry.4th ed, India: JAYPEE publishers; 1999: 31.

10. Parashar S.S.L. Principles of sociology and health care. In Social Behavioral and Communication sciences. [Internet] 4; 113: 611. (cited on 1.4. 2009) Available in http:// www.whoindia.org /Link Files / Human_Resources_Section4-Textbook_on_ Public_Health_ and Community_ Medicine. pdf

11. Rabbani S., Ahammed I. and Ahmed N. A community based detoxification programme, useful initiative for advocacy strategy for harm reduction programme. Bangladesh 2010.

12. Ahmmed S.K. Vulnerability for HIV epidemic in conceptual understanding of drug abuse treatment. Bangladesh 2009.

13. Bowman K. R., Chromy J. R., Odom D. M. and Penne M. A. (2003 April). 2001 National household survey on drug abuse: Sample design report. In 2001 National household survey on drug abuse: methodological resource book: (vol 1 sec 2 prepared for the Substance Abuse and Mental Health Services Administration, Office of Applied Studies, under contract No: 283-989008, deliverable no. 10, RTI/07/90.330.400). Research triangle park NC: RTI, (Cited on 29.10.2011) (Available as PDF at http:// www.oas.samhsa.gov /nhsda/ methods.cfm\#2k1)

14. Doussantousse S., Thanh Hoa N. and Peter Higgs P. The social environment of IDUs in Hanoi, Vietnam: Fifth ICAAP- Melbourne 2001.

15. Nessa A., Latif S.A., Siddiqui N.I., Hussain M.A. and Hossain M.A. Drug abuse and addiction. Mymensingh Med J.2008Jul: 17(2): 227-35.

16. Ray R. (Editor). Drug abuse among prison population. Ministry of Social Justice and Empowerment Govt. of India, and United Nations International Drug Control Programme, June 2002.

17. Mohan D. and Desai N.G. (1994). "A survey of drug dependence in the community, urban megapolis Delhi: survey resurvey." Report submitted to Indian Council of Medical Research (ICMR).

18. Mufti K.A., Said S., Farooq S., Haroon A., Nazeer A., Naeem S. et al. 5 year followup of 100 heroin addicts in Peswar. [internet] $J$ Ayub Med Coll Abbottabad. 2004 Jul-Sep; 16(3):59

19. Chaturvedi H.K. and Mahanta J. Sociocultural diversity and substance use pattern in Arunachal Pradesh, India. Drug Alcohol Depend.2004 Apr; 74(1):97-104.

20. Zhang, Z., Huang, L. X., and Brittingham, A. M. (1999). Worker drug use and workplace policies and programs: Results from the 1994 and 1997 National household survey on drug abuse. (Report No. DHHS Publication No. SMA 99-3352, Analytic Series A-11). Rockville, MD: Substance Abuse and Mental Health Services Administration, Office of Applied Studies. (Cited on 30.12.2008) [Available at http:// www.oas. samhsa. gov/ analytic.htm]

21. Hazarika N.C., Biswas D., Phukan R. K., Hazarika D. and Mahanta J. Prevalence and pattern of substance abuse at Bandardewa, a border area of Assam and Arunachal Pradesh. Ind J Psychiatry.2000, 42(3): 262-66. 
22. Regier D. A., Farmer M. E., Rae D. S., Locke B. Z., Keith S. J., Judd L. L. et al. Co morbidity of mental disorders with alcohol and other drug abuse. J of the Am Med Assoc 1990; 264: 2511-18.

23. Chaturvedi H. K., Phukan R. K. and Mahanta $\mathrm{J}$. The association of selected sociodemographic factors and differences in patterns of substance use : a pilot study in selected areas of North East India. Subst Use Misuse. 2003 Jul; 38(9): 1305-22.

24. Agrawal D., Lal A. and Chandra R. Relapse precipitants in alcohol addiction. Ind J Soc Sc Res. 2009(March); 6(1):80-83.

25. Montoya I.D., Haertzen C., Hess J.M. and Covi L. Comparison of psychological symptoms between drug abusers seeking and not seeking treatment. $J$ of Nerv and Ment Dis. 1995; 183: 50-53.

26. Anthony J.C. and Helzer J.E. Syndromes of drug abuse and dependence. In Robins, L.N. and
D.A. Regier (Eds.). 1991. Psychiatric disorders in America. New York. Free Press: 116-54.

27. Alverson H., Alverson M. and Drake R.E. Social patterns of substance use among people with dual diagnoses. Ment Hlth Serv Res. 2001; 3:3-14.

28. Quimby E. Homeless clients' perspectives on recovery in the Washington, DC, dual diagnosis project. Contemporary drug problems summer.1995; 265-89.

29. Sells D.J., Rowe M. and Fisk D. Violent victimization of persons with co-occurring psychiatric and substance use disorders. Psych Serv.2003; 54:1253-57.

30. Salyers M., Becker D.R. and Drake R.E. A tenyear follow-up of supported employment. Psych Serv. 2004; 55:302-08.

31. Heyman G. M. Resolving the contradictions of addiction. Behav and Brain Sc. 1996; 19: 561-74. 